\title{
Modeling and Control System Design of Marine Controlled-Source Electromagnetic Detection Transmitter
}

\author{
Tao Haijun ${ }^{*}, 1,2$, Zhang Yiming ${ }^{1}$ and Ren Xiguo ${ }^{1}$ \\ ${ }^{I}$ College of Electronic Information and Control Engineering, Beijing University of Technology, Beijing 100124, P.R. \\ China \\ ${ }^{2}$ School of Electrical Engineering and Automation, Henan Polytechnic University, Jiaozuo, Henan, 454003, P.R. China
}

\begin{abstract}
Marine electromagnetic transmitter transmits large power variable frequency electromagnetic wave to the seabed so as to obtain the submarine structure and mineral resources. The mathematical model of controlled source circuit needs to be established to realize closed loop control for increasing control precision and output transient performance of the electromagnetic wave. The operation process of controlled circuit is analyzed in continuous current mode, two equivalent switching states of controlled source circuit are obtained through the analysis of the different states of the switch in a switching period. A small signal equivalent model of the system is established using small ripple approximation. For high output voltage fluctuation problem in single loop control, double loop control strategy of voltage loop and current loop is designed. The simulation and experimental results show that, the system has the advantages of fast transient response speed and good regulation performance.
\end{abstract}

Keywords: Controlled source circuit, dual-closed loop, marine electromagnetic detection transmitter, modeling.

\section{INTRODUCTION}

The exploration and exploitation of marine resources has the high cost of drilling and investment risk. In order to improve the success rate of drilling, before well drilling the world's major oil companies always carries out a variety of exploration like seismic, gravity, magnetic, etc. [1]. The marine controlled source electromagnetic detection has become one of the most important means to reduce the risk in deep-water drilling oil and gas resources for distinguishing between oil and water traps nature, exposing "the high impedance body" under the coverage [2]. Marine controlled source electromagnetic detection system supplies the transmitter on the seabed by tug. The multi-component electromagnetic receiver laid on the seabed measures electromagnetic field values. Calculating the apparent resistivity and phase, or using directly the electric and magnetic fields detect distribution characteristics of the underground electrical. It can reveal the distribution of the underlying structure, oil and gas and other mineral resources [3].

From the 1970s, the marine electromagnetic survey techniques and instruments have been developed. The Mainly organization are the United States Scripps Institution of Oceanography (SIO), the German Leibniz Institute of Marine Sciences (IFM-GEOMAR), the British Association of subsea equipment (OCIB) and Japan TIERRA Companies [4]. While the world's major marine electromagnetic

*Address correspondence to this author at the College of Electronic Information and Control Engineering, Beijing University of Technology, Beijing 100124, P.R. China; Tel: +86 01067396621 ;

Fax:+8601067396621; E-mail: taohj99@hpu.edu.cn detection service companies (such as Norway EMGS, British OHM Corporation, the United States, AGO, British MTEM, etc.) have been established, and carried out a number of marine electromagnetic detection projects [5].Currently marine electromagnetic transmitter has a large size and weight, low efficiency, and poor transient waveform emitted, can't meet the needs of the oil exploration industry practice.

In order to reduce the volume and weight of the transmitter circuit, high-frequency switching power supply circuit topology is used [6]. In order to obtain good dynamic and static performance, the control loop must be designed accordingly [7]. The control loop design is closely related to structure and parameters of the main circuit [8]. Therefore, before designing the control system, mathematical model of controlled source circuit needs to establish. In the literature [9-11], the circuit models of Buck, Boost, Buck-Boost are analyzed, but these circuits can be used only a few kilowatts of small power applications, while marine electromagnetic detection transmitter output power is up to dozens or even hundreds $\mathrm{kW}$ [12], the full-bridge circuit controlled source circuit must be used for electrical energy conversion. This paper analyzes the operation process of controlled source circuit, through the analysis of different switching states in a switching cycle, two equivalent switching states of controlled source circuit are obtained, mathematical model of the system is established using small signal approximation method, and double closed loop control system is designed.

\section{OPERATION PRINCIPLE OF MARINE ELECTRO- MAGNETIC DETECTION TRANSMITTER}

The operation principle of marine controlled source electromagnetic detection system is shown in Fig. (1). The 
system includes ship board diesel generators, deck-side rectifier filter circuits, deck-side PC monitor unit, underwater streamers, DC/DC controlled source circuits, launch circuits, the emitter electrode, the control unit of the transmission system, and carrier communication etc.

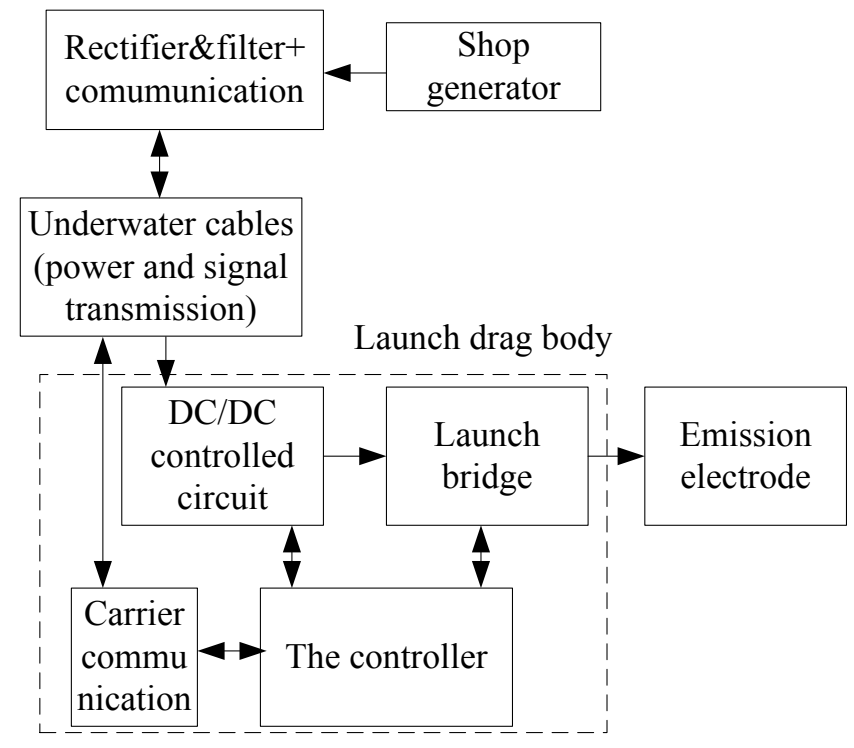

Fig. (1). Circuit diagram of the transmitter.

The shipboard generator provides the initial energy for the whole controlled source electromagnetic detection system. The deck-side rectifier filter circuits rectify the three-phase AC voltage generated by the generator into a direct current, reducing the transmission loss by shipboard towing. After the electromagnetic detection transmitter gets the seabed, the deck-side PC monitor unit can establish remote communications between underwater streamer and the control unit of the transmitter. While the deck-side PC monitor unit also has a time service function for the whole system. The ship underwater streamers connect the ship and the transmitter for power and signal transmission. Underwater DC/DC controlled source circuits transform the high-voltage direct current by the underwater streamers to a controllable DC current. Then the launch circuits reverse this controllable DC current into a frequency tunable square wave AC current. At last, the final current would be transmitted by the emitter electrode to the seawater. The control unit of the transmission system with dual DSP could achieve control the DC-DC controlled source circuits and the launch circuits and detect the transmitter state. The underwater carrier communication, establishes a communication connection with the transmitter and PC monitor unit.

The DC/DC controlled source circuit is a key part of marine electromagnetic detection transmitter, and its dynamic characteristics and efficiency directly affects the performance of the entire transmitter. For increasing the output voltage and current control accuracy, it requires the use of closed-loop control system. Firstly, the operation process of controllable source circuit is analyzed, smallsignal model of marine transmitter controlled source circuit is established and the control system is designed.

\section{OPERATION PROCESS OF CONTROLLED SOURCE CIRCUIT}

Controlled source circuit structure is shown in Fig. (2), including inverter, dual output transformer with a centertapped, full-wave rectifier and LC filter circuit. Parallel connect of the transformer output, only can achieve automatic current for the output rectifier diodes, also make the modular design of the transformer, and simplify the production process of the transformer and reduce losses. Controlled source circuit is using bipolar control, the value of the output voltage can be controlled by adjusting the duty ratio.

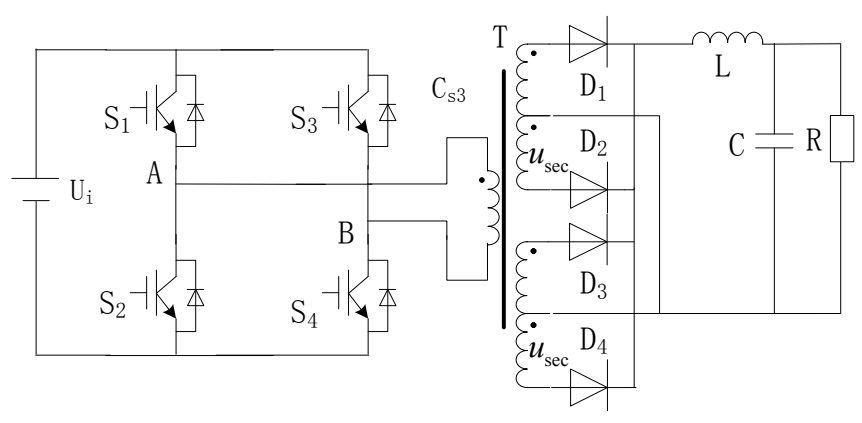

Fig. (2). Controlled circuit principle diagram.

When the controllable current source circuit is operating in the continuous mode, each switching cycle has four operating states as shown in Fig. (3). From Fig. (3a, b) can be seen, although the current flows through different switches and diodes in two operation states, the current direction is consistent looking from the transformer primary to the secondary, only primary and secondary current of the transformer flows from the inflow and outflow of different dot end, and then switching status shown in Fig. (3a, b) can be combined into equivalent state 1 shown as in Fig. (4a). Similarly, switching status shown in Fig. (3c, d) can be combined into the equivalent state 2 as shown in Fig. (4b).

\section{SMALL SIGNAL EQUIVALENT CIRCUIT MODELING}

In the equivalent state $1, \mathrm{KVL}$ and $\mathrm{KCL}$ equations are as follow

$$
\begin{aligned}
& u_{L}(t)=n * u_{g}(t)-u_{o}(t) \\
& i_{C}(t)=i_{L}(t)-u_{o}(t) / R_{L} \\
& i_{g}(t)=n * i_{L}(t)
\end{aligned}
$$

Similarly, in the equivalent state 2

$$
\begin{aligned}
& u_{L}(t)=u_{o}(t) \\
& i_{C}(t)=i_{L}(t)-u_{o}(t) / R_{L} \\
& i_{g}(t)=0
\end{aligned}
$$

Under the condition of low frequency, using small ripple approximation, voltage and current are replaced by its average value.

$u_{L}(t)=n^{*}<u_{g}(t)>_{T_{s}}-<u_{o}(t)>_{T_{s}}$ 
$i_{C}(t)=<i_{L}(t)>_{T_{s}}-<u_{o}(t)>_{T_{s}} / R_{L}$

$i_{g}(t)=n^{*}<i_{L}(t)>_{T_{s}}$

$u_{L}(t)=<u_{o}(t)>_{T_{s}}$

$i_{C}(t)=\left\langle i_{L}(t)>_{T_{s}}-<u_{o}(t)>_{T_{s}} / R_{L}\right.$

$i_{g}(t)=0$

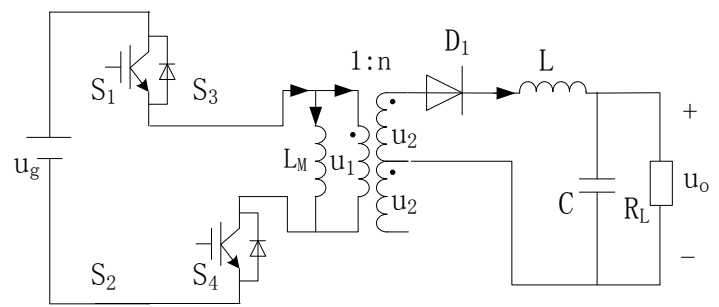

(a)

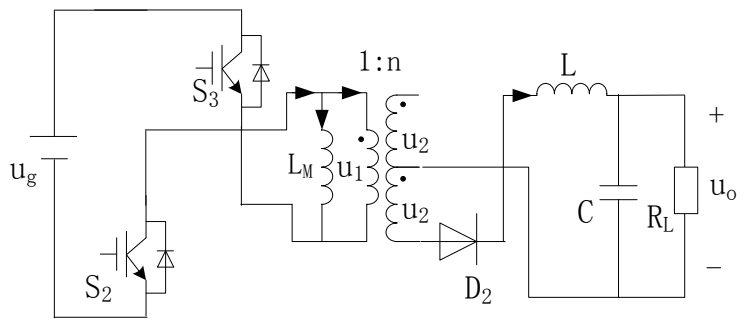

(b)

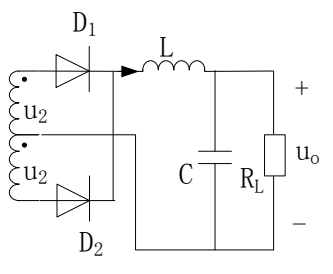

(c)

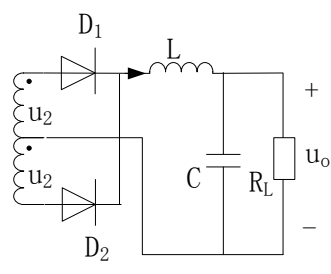

(d)
Fig. (3). Switching states of controlled source circuit in CCM.

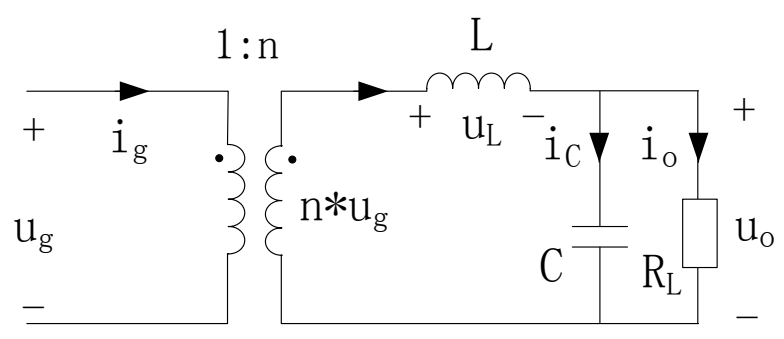

(a)

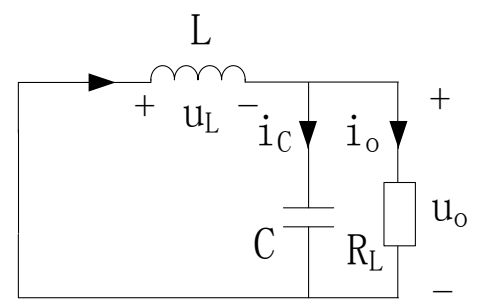

(b)

Fig. (4). Equivalent switching states.
In one cycle, the instantaneous value of the inductor currents and capacitor voltages can be approximate with their average value.

$$
\begin{aligned}
& L \frac{d<i_{L}(t)>_{T_{s}}}{d t}=d(t) *\left[n^{*}<u_{g}(t)>_{T_{s}}-\right. \\
& \left.<u_{o}(t)>_{T_{s}}\right]+d^{\prime}(t) *\left[-<u_{o}(t)>_{T_{s}}\right] \\
& L \frac{d<u_{C}(t)>_{T_{s}}}{d t}=d(t) *\left[<i_{L}(t)>_{T_{s}}-<u_{o}(t)>_{T_{s}}\right. \\
& \left./ R_{L}\right]+d^{\prime}(t) *\left[<i_{L}(t)>_{T_{s}}-<u_{o}(t)>_{T_{s}} / R_{L}\right] \\
& <i_{g}(t)>_{T_{s}}=d(t) * n^{*}<i_{L}(t)>_{T_{s}}+d^{\prime}(t) * 0
\end{aligned}
$$

The average values are separated into the quiescent point + perturbation.

$$
\begin{aligned}
& <U_{g}(t)>_{T_{s}}=U_{g}+\hat{u}_{g}(t) \\
& <d(t)>_{T_{s}}=D+\hat{d}(t) \\
& <d^{\prime}(t)>_{T_{s}}=1-D-\hat{d}(t) \\
& <i_{L}(t)>_{T_{s}}=I_{L}+\hat{i}_{L}(t) \\
& <u_{o}(t)>_{T_{s}}=U_{o}+\hat{u}_{o}(t) \\
& <i_{g}(t)>_{T_{s}}=I_{g}+\hat{i}_{g}(t)
\end{aligned}
$$

Substitute (16) (21) into (13)

$$
\begin{aligned}
& L \frac{d\left(I_{L}+\hat{i}_{L}(t)\right)}{d t}=(D+\hat{d}(t)) *\left[n *\left(U_{g}+\hat{u}_{g}(t)\right)-\right. \\
& \left.\left(U_{o}+\hat{u}_{o}(t)\right)\right]+(1-D-\hat{d}(t)) *\left[-\left(U_{o}+\hat{u}_{o}(t)\right)\right]
\end{aligned}
$$

Ignoring the second term, the small signal model equations can be obtained by making the corresponding exchange terms equal

$L \frac{d \hat{i}_{L}(t)}{d t}=n D \hat{u}_{g}(t)+n \hat{d}(t) U_{g}-\hat{u}_{o}(t)$

Similarly available

$$
\begin{aligned}
& L \frac{d \hat{u}_{C}(t)}{d t}=\hat{i}_{L}(t)-\frac{\hat{u}_{o}(t)}{R} \\
& \hat{i}_{g}(t)=n * D * \hat{i}_{L}(t)+n * I_{L} * \hat{d}(t)
\end{aligned}
$$

According to the above equations, s-domain small-signal equivalent circuit model shown in Fig. (5) can be obtained by substituting the ideal DC transformer model and transforming into the s-domain.

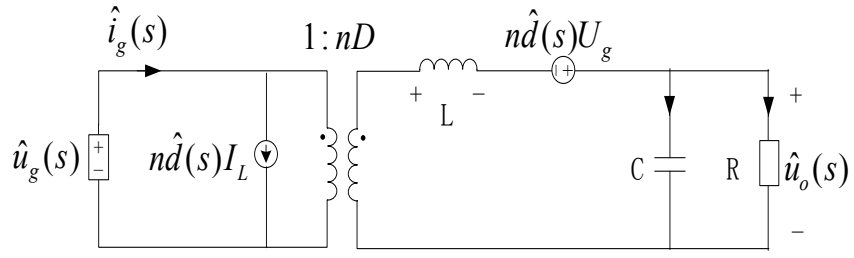

Fig. (5). Small signal equivalent circuit of s domain. 


\section{CONTROLLED SOURCE CIRCUIT DUAL-LOOP CONTROL SYSTEM DESIGN}

\subsection{Dual-Loop Control System Principle}

Dual closed-loop control system using digital PI control algorithm is shown in Fig. (6), including the inner current loop and outer voltage loop. The inner current loop not only limits the output current, but also improves the dynamic response of output and reduces the output voltage ripple. Specific operation principle as follows: output voltage $u_{o}$ of controlled source circuit compares with the reference voltage $u_{r e f}$ through the voltage sampling circuit to obtain a voltage error signal $u_{V}$ which provide a reference signal for the current control loop through the voltage PI regulator. Filter inductor current $i_{L}$ compares with $u_{V}$ to obtain the current error signal through the current sampling circuit, the controlled voltage $u_{A}$ generates through the current PI regulator, the PWM driving wave of duty cycle $d$ through PWM modulation drive the IGBT inverter bridge, then the output voltage $u_{o}$ can be controlled.

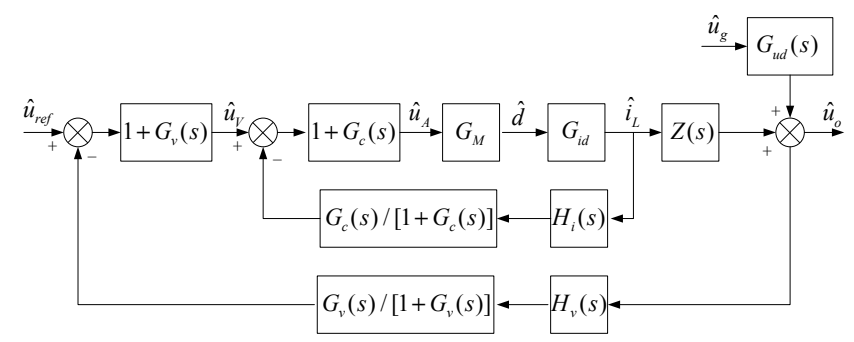

Fig. (6). Dual-closed loop control system block diagram.

\subsection{Design of Current Regulator}

Assuming that the disturbances of input voltage $\hat{u}_{g}$ and output voltage $\hat{u}_{o}$ is zero, the perturbation of voltage controller output voltage $\hat{u}_{c p}=0$; current sampling resistor is very small. Inductor current detection is achieved by sampling resistor $R_{s}, R_{s} \ll s L$. According to small-signal equivalent model of the controlled source circuit, ignoring $R_{s}$, the transfer function $G_{i d}$ of object controlled by the current regulator is as follow

$G_{i d}=\frac{\hat{i}_{L}}{\hat{d}}=\frac{n U_{g}}{s L}$

The transfer function for PWM modulator

$G_{M}=\frac{\hat{d}}{\hat{u}_{A}}=\frac{1}{U_{M}}$

where, $U_{M}$ is peak voltage of the sawtooth wave.

Current feedback transfer function $H_{i}=R_{s}$, the open loop transfer function of current control target is
$G_{c o}=G_{M} G_{i d} H_{i}=\frac{n U_{g} R_{s}}{U_{M} L s}$

The transfer function $G_{c o}(s)$ shows that the control object of the current regulator is integral type for controlled source circuit. For integral type control object, according the principle that to the down slope of amplified inductor current can't exceed the rising slope of the sawtooth wave [13], maximum gain of controlled current source circuit compensation network at switching frequency can be obtained.

$G_{c \max }(s)=\frac{U_{M} f_{s} L}{U_{o} R_{s}}$

For integral type control objects, there are the following two requirements in the design of its current regulator [14], (1) The gain of circuit compensation network in the range from crossover frequency to switching frequency is approximately equal to $G_{c \max }(s)$. Namely, amplitudefrequency characteristics in the band have a flat characteristic. (2) Phase margin has sufficient at the crossover frequency. Given the above considerations, single pole/zero compensation network (Fig. 7) can meet the requirements.

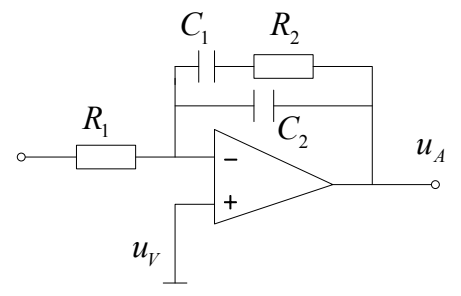

Fig. (7). Compensation circuit with a pole/zero pair.

Under the condition of $C_{2} \gg C_{1}$, single pole/ zero compensation network transfer function is as follow

$G_{c}(s)=K_{c} \frac{1+\omega_{c z} / s}{1+s / \omega_{c p}}$

where, the compensation network gain: $K_{c}=G_{c \max }$, $\approx R_{2} / R_{1}$; current compensation network pole angular frequency: $\omega_{c p}=1 / R_{2} C_{1}$; current compensation network zero angular frequency: $\omega_{c z}=1 / R_{2} C_{2}$.

The high frequency pole $f_{p}$ is provided with the switching frequency $f_{s}$, i.e. $f_{p}=f_{s}$, in the place of $f_{s}$, the gain of compensation network $G_{c}=R_{2} / R_{1}=G_{\max }$, then

$\frac{R_{2}}{R_{1}}=\frac{U_{M} L f_{s}}{U R_{s}}$

In order to ensure adequate phase margin, the proposed zero crossing frequency is set at half the frequency, then 
$\frac{1}{2 \pi R_{2} C_{2}}=0.5 f_{c}=0.5 \frac{f_{s}}{2 \pi n D}$

For $f_{p}=f_{s}, C_{2} \gg C_{1}$, then

$\frac{1}{2 \pi R_{2} C_{1}}=f_{s}$

In order to make compensate network wide enough in the band to increase the phase margin, taking

$C_{2}=(10 \sim 25) C_{1}$

Solving (31) (34), the parameters of current compensation network can be obtained.

\subsection{Obtain Control Target of Voltage Regulator}

Control target of voltage regulator are composited by the current control loop and load.

(1) Current loop transfer function

Because the output of voltage regulator $\hat{u}_{V}$ is connected to the operational amplifier noninverting input, with $\hat{u}_{V}$ as input, the transfer function of the current regulator becomes $1+G_{c}(s)$. Therefore, the feedback channel increased the link of $G_{c}(s) /\left[1+G_{c}(s)\right]$ in Fig. (8).

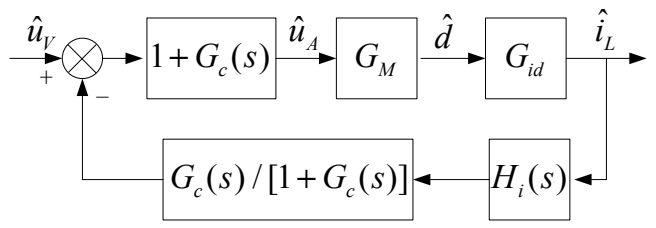

Fig. (8). Current close-loop diagram.

Closed-loop transfer function of the current loop can be obtained according to Fig. (8).

$G_{c c}(s)=\frac{G_{M}(s) G_{i d}(s)\left[1+G_{C}(s)\right]}{1+G_{M}(s) G_{i d}(s) G_{C}(s)}$

Visible, the closed-loop transfer function of the current loop is a higher-order system, which needs to reduce order when designing voltage outer-loop. Simplified model is as follow.

$$
G_{c c}^{\prime}(s)=\frac{1}{R_{s}} * \frac{1}{\frac{s^{2}}{\left(\omega_{c p} / 2\right)}+\zeta \frac{s}{\omega_{c p} / 2}+1}
$$

where, $\zeta=1 \sim 1.5$

(2) Transfer function of control object for voltage regulator

Load segment Z (s) is composed by the output filter capacitor $\mathrm{C}$ and load resistor $\mathrm{R}$, whose transfer function is:

$$
Z(s)=K_{Z} \frac{s / \omega_{z z}+1}{s / \omega_{z p}+1}
$$

where, the network load gain $K_{Z}=R_{L}$; pole angular frequency of load $\omega_{z p}=1 /\left[\left(R_{C}+R_{L}\right) C\right]$; zero angular frequency of the load $\omega_{z z}=1 /\left(R_{C} C\right) . R_{C}$ is equivalent series resistance of output filter capacitor.

After using the current loop approximation closed loop transfer function $G_{C C}^{\prime}(s)$ to instead $G_{C C}(s)$, the transfer function of equivalent power stage is as follow.

$$
G_{E P L}(s)=\frac{R_{L}}{R_{s}} \frac{\frac{s}{\omega_{z z}}+1}{\left(\frac{s}{\omega_{z p}}+1\right)\left[\frac{s^{2}}{\left(\omega_{c p} / 2\right)}+\zeta \frac{s}{\omega_{c p} / 2}+1\right]}
$$

\subsection{Voltage Regulator Design}

Because the voltage control object has three poles and one zero, which needs to increase two zeroes to offset the corresponding poles, it requires the use of double pole/zero pair compensation network as voltage compensation network as shown in Fig. (9).

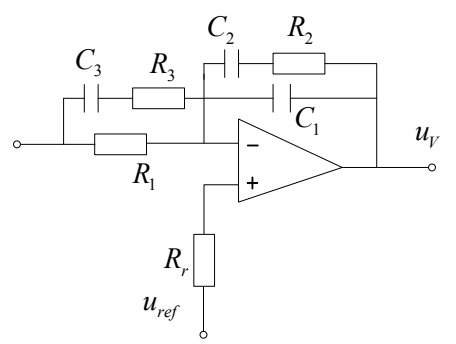

Fig. (9). Compensation circuit with dual pole/zero pair.

Under the conditions of $C_{2} \gg C_{1}$ and $R_{1} \gg R_{3}$, transfer function of double pole/zero pair compensation network is as follow.

$G_{U}(s)=K_{U} \frac{\left(1+\omega_{u z 1} / s\right)\left(1+s / \omega_{u z 2}\right)}{\left(1+s / \omega_{u p 1}\right)\left(1+s / \omega_{u p 2}\right)}$

where, $K_{U}$ is gain of compensation network, $\omega_{u p 1}$ is the first pole angular frequency; $\omega_{u p 2}$ is the second pole angular frequency; $\omega_{u z 1}$ is the first zero angular frequency; $\omega_{u z 2}$ is the second zero angular frequency.

When the across frequency of voltage control loop $\omega_{u c}$ is less than the pole angular frequency $\omega_{c p}$ of current control loop compensation network, gain of voltage compensation network is as follow.

$$
K_{U}=\frac{R_{s} \omega_{u c}}{R_{L} H \omega_{z p}}
$$

$\omega_{z p}$ is pole angular frequency of load.

Make the first pole $f_{u p 1}$ offset the ESR zero of equivalent power, $f_{u p 1}=f_{z 0}$, then 
$\omega_{p 1}=\frac{1}{R_{3} C_{3}}$

Set the first pole $f_{u z 1}$ is located near zero of load, $f_{u z 1}=f_{p 01}$

$\omega_{z 1}=\frac{1}{R_{2} C_{2}}$

Make second zero $f_{u z 2}$ offset a pole $f_{p 02}$ of current loop, $f_{u z 2}=f_{p 02}=f_{s} / 2$

$\omega_{z 2}=\frac{1}{R_{1} C_{3}}$

In order to reduce the impact of the second pole, so $f_{u p 2}$ locates near the switching frequency, $f_{u p 2}=f_{s}$, to increase high frequency attenuation rate.

$\omega_{p 2}=\frac{1}{R_{2} C_{1}}$

We can get the parameters of voltage regulator compensation network by (41) to (44).

\section{SIMULATION AND EXPERIMENT}

Based on the above analysis, a $6 \mathrm{~kW}$ marine electromagnetic detection transmitter is designed as shown in Fig. (10). The main parameters: input voltage $U_{g}=300 \mathrm{~V}$, output voltage $U_{o}=34 \mathrm{~V}$, output current $I_{o}=200 \mathrm{~A}$, filter inductor $L=60 u H$, filter capacitor $L=500 \mu \mathrm{F}$, the sampling resistor $R_{s}=15 \mathrm{~m} \Omega$, sawtooth peaks $U_{M}=5 \mathrm{~V}$.

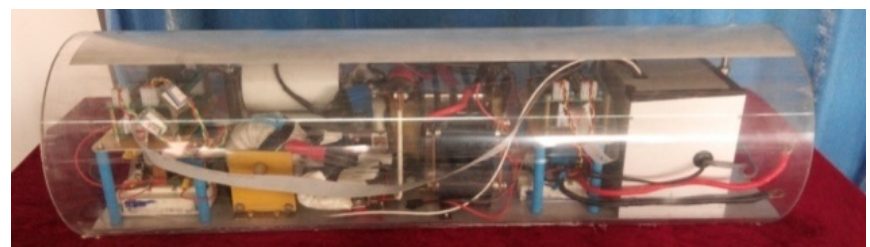

Fig. (10). Physical picture of marine electromagnetic transmitter.

\subsection{Simulation Results and Analysis}

According to open-loop and closed-loop transfer function of the inductor current, bode plots of open-loop and closedloop transfer function before and after current compensation is shown in Fig. (11). The figure shows that, cut-off frequency is $4.77 \mathrm{kHz}$, and is located in the slope of $20 \mathrm{~dB} / \mathrm{dec}$ segment, the response of the system is quickly. Phase margin is $48^{\circ}$ and adequate, the system is stable.

According to open-loop and closed-loop transfer function of the output voltage, bode plots of open-loop and closedloop transfer function before and after voltage compensation is shown in Fig. (12). The figure shows that, the cut-off frequency is $14 \mathrm{kHz}$, the phase margin is $50^{\circ}$. In the low and mid frequencies, slope decline of amplitude-frequency curve is $-20 \mathrm{~dB} / \mathrm{dec}$, which shows steady-state error of the system is zero, phase margin is sufficient, the voltage control loop is stable. The slope of amplitude-frequency curve is $-40 \mathrm{db} / \mathrm{dec}$ at high frequencies, the system has a good anti-jamming ability.

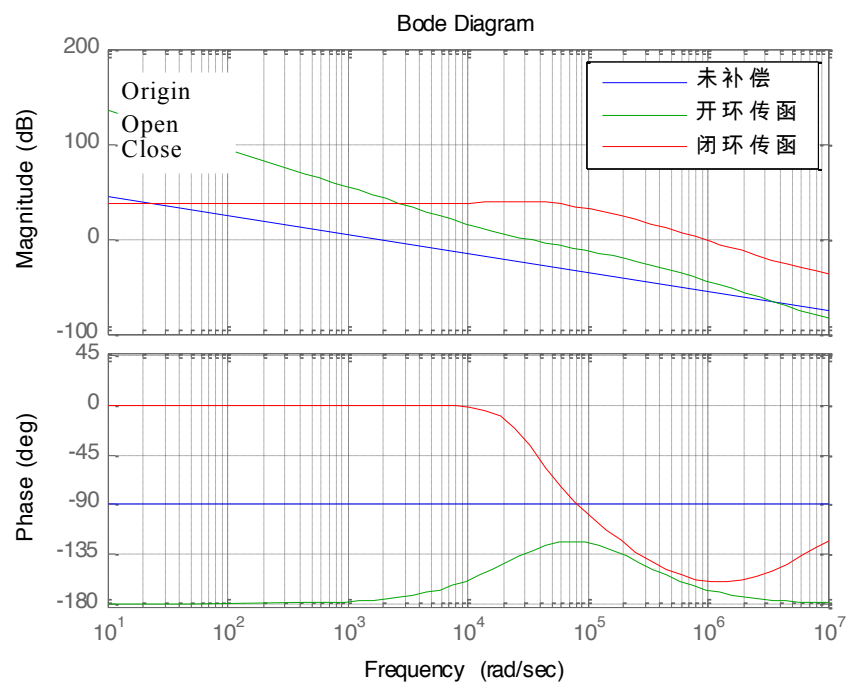

Fig. (11). Bode diagram of current inner loop.

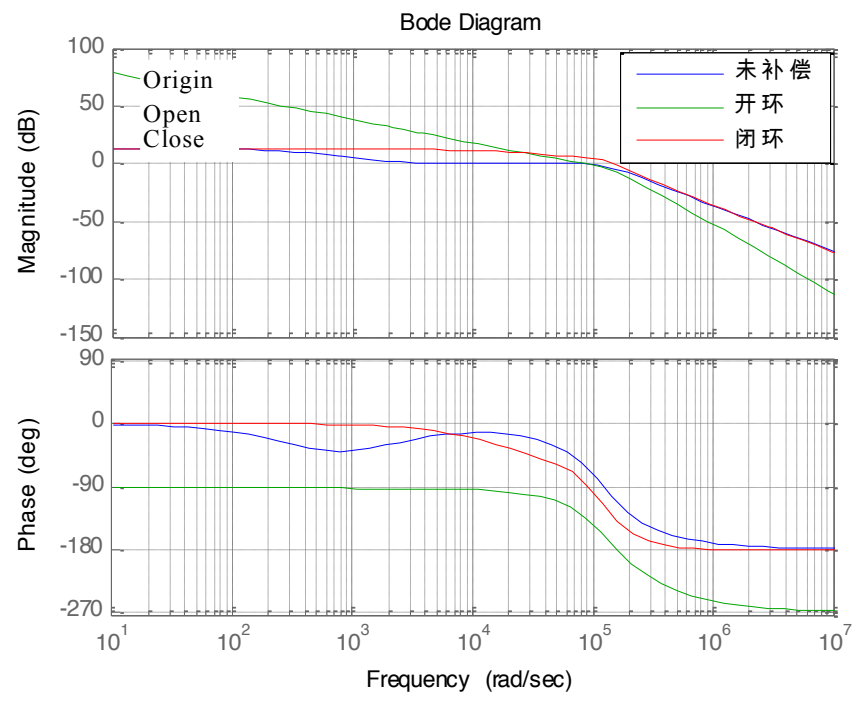

Fig. (12). Bode diagram of voltage outer loop.

\subsection{Experimental Results and Analysis}

Primary and secondary voltage and current waveforms of transformer in the marine electromagnetic detection transmitter controlled source circuit are shown in Fig. (13). As can be seen from the figure, the experimental results and the theoretical analysis are consistent, taking into account the impact of the transformer leakage inductance, primary voltage and current waveforms are approximately the same due to the use of bipolar control mode. The secondary voltage shocks occur due to carrier recombination of high frequency rectifier diodes.

Output voltage and current waveforms of transmitter with single loop voltage control and voltage and current double 
closed-loop control are shown in Figs. $(\mathbf{1 4}, \mathbf{1 5})$ respectively. Emission frequency is $2 \mathrm{~Hz}$, transmit voltage is $34 \mathrm{~V}$, the emission current is $200 \mathrm{~A}$, using dual loop control system, the transient performance of electromagnetic output has clearly improved.

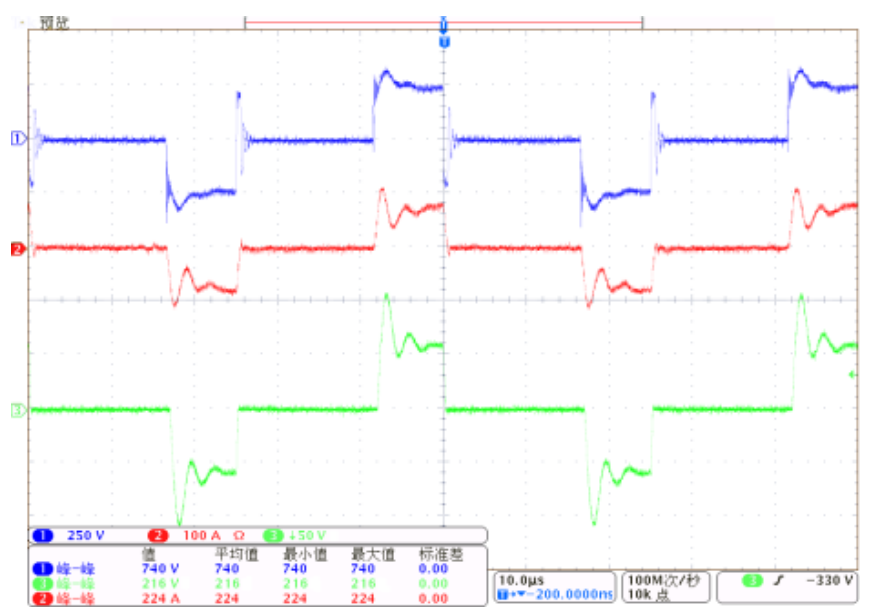

Fig. (13). Voltage and current waveforms of transformer.

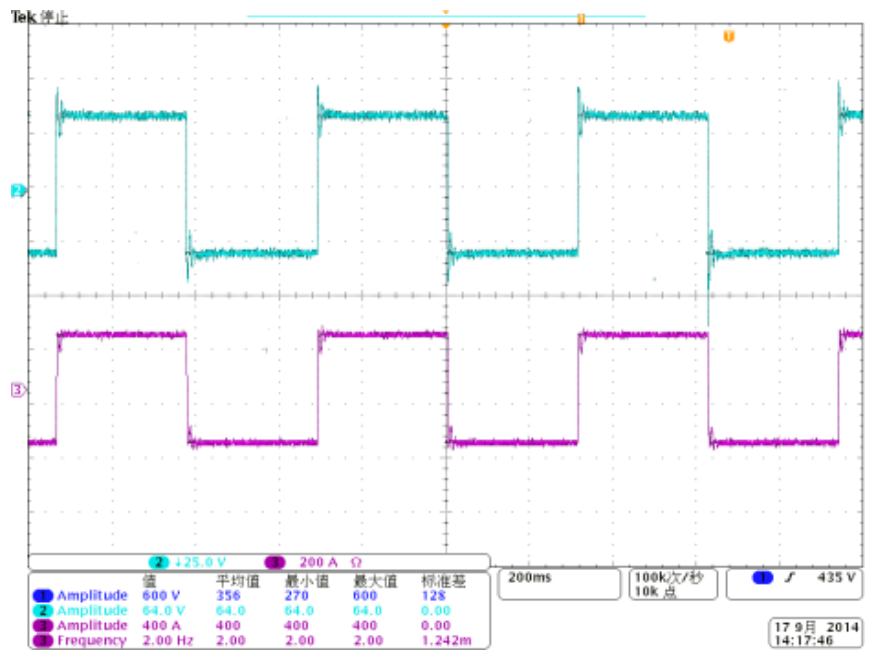

Fig. (14). Output voltage and current waveforms of transmitter transmitting electrode with single loop.

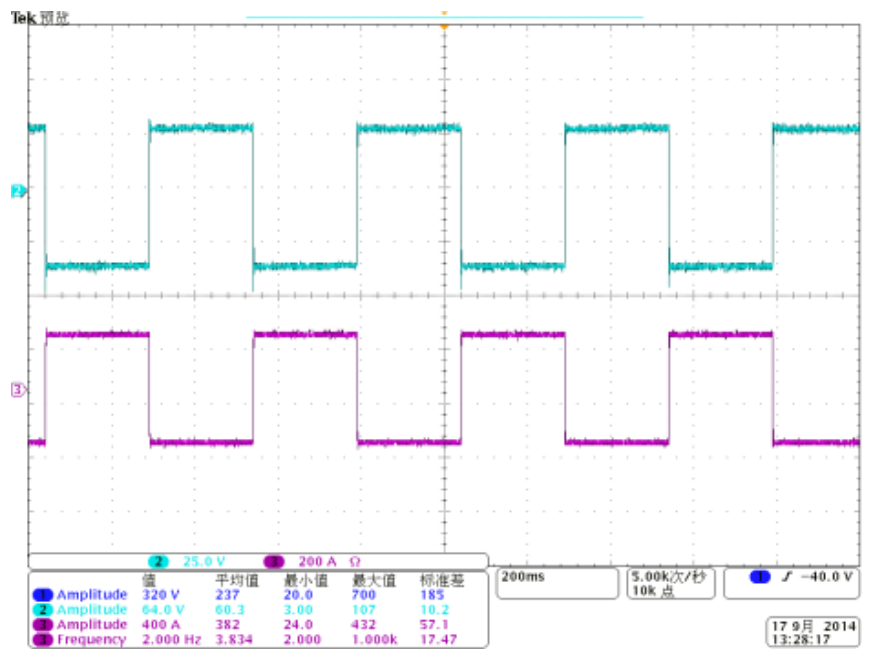

Fig. (15). Output voltage and current waveforms of transmitter transmitting electrode with dual loops.
Measure efficiency curve of marine electromagnetic detection transmitter is shown in Fig. (16). The maximum efficiency of Marine electromagnetic detection transmitter using dual-loop control is up to $83 \%$.

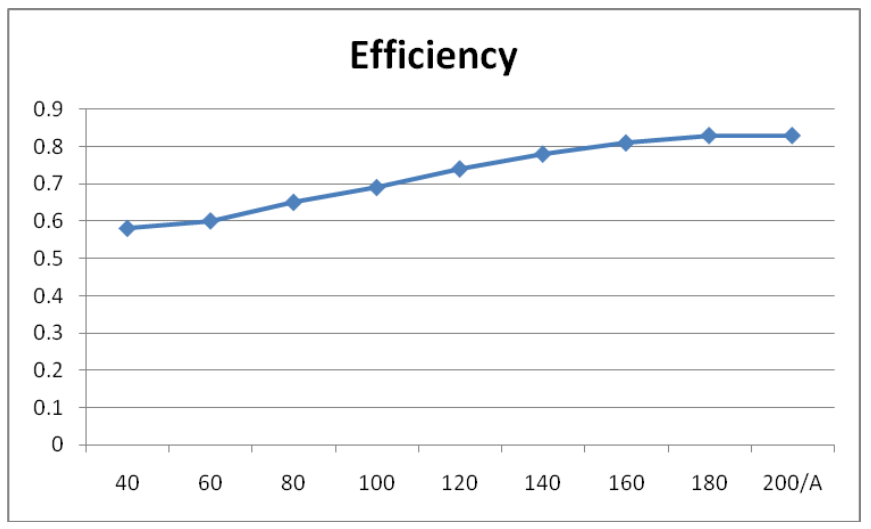

Fig. (16). Measure efficiency of marine electromagnetic detection transmitter.

\section{CONCLUSION}

The operation process of marine electromagnetic detection transmitter controlled source circuit is analyzed, through the analysis of different switching states in a switching cycle, two equivalent switching states are obtained when controlled source circuit is operating, as a basis we can establish controlled source circuit mathematical model.

The small-signal model of controlled source circuit is established using small ripple approximation method. The model not only can directly reflect the role that controlled source circuit converts the DC voltage, and may reflect the transfer process of small signal and the low-frequency characteristics in controlled source circuit.

The double closed loop control strategy of the current inner loop and voltage outer loop is designed for the presence of output current fluctuations, and poor transient in single-loop control. The simulation and experimental results show that the system output electromagnetic waves has fast transient response and good regulation performance.

\section{CONFLICT OF INTEREST}

The author confirms that this article content has no conflict of interest.

\section{ACKNOWLEDGMENTS}

Authors wishing to acknowledge assistance or encouragement from colleagues, financial support by $R \& D$ of Key Instruments and Technologies for Deep Resources Prospecting (the National R\&D Projects for Key Scientific Instruments), GrantNo. ZDYZ2012-1-05-01 and Henan province science and technology key project, GrantNo.142102210048.

\section{REFERENCES}

[1] M. Kurang, N. Misac, and Y. Li, "Con-trolled Source Electromagnetic(CSEM) technique for detection and delineation of 
hydrocarbon reservoirs: an evaluation," Expanded Abstracts of 75thAnnual Internat SEG Mtg, European, pp.546-549, 2005.

[2] S. Constable, A. Orange, and G.M. Hoversten, "Marine magnetotellurics for petroleum exploration Part ̃̃: A sea-floor instrument system", Geophysics, vol.63, no.3, pp.816-825, 1998.

[3] S. Constable, and L. J. Srnka, "An introduction to marine controlled-source electromagnetic methods for hydrocarbon exploration", Geophysica, vol.72, no.7, pp. 3-12, 2007.

[4] T. Eidesmo, S. Ellingsrud, and L. M. Macgregor, "Remote detection of hydrocarbon filled layers using marine controlled source electromagnetic sounding", EAGE $64^{\text {th }}$ Conference \& Exhibition, Florence, Italy, pp.27-30, 2002

[5] S. Constable, and L. J. Srnka, "An introduction to marine controlled source electromagnetic methods for hydro-carbon exploration", Geophysics, vol.72, no.2, pp. 3-12, 2007.

[6] R. Erichson, and D. Maksimovic, "Fundamentals of power electronics", New York: Kluwers Academic Press, pp.187-258, 2001.

[7] R. Kollman, and J. Betten, "Closing the Loop with a Popular Shunt Regulator", Power Electron. Technol., vol.46, no.2, pp. 30-36, 2003.
[8] D. Middlebrook, and S. Cuk, "A General Unified Approach to Modeling Switching-converter Power Stage", Int. J. Electron., vol.42, no.6, pp.521-550, 1977.

[9] R. B. Ridley, "A New Continuous-Time Model for Current-Mode Control”, IEEE Trans. Power Electron., vol.34, no.6, pp.271-280, 1991.

[10] V. Vorperian, "Simplified Analysis of PWM Converters Using the Model of the PWM Switch: Parts I and II", IEEE Trans. Aerosp. Electron. Syst., vol.52, no.26, pp. 490-505, 1990.

[11] S. V. Mollov, and M. Theodoridis, "A tforsyth, high frequency votagefed invert with phaseshife control for induction heating", IEEE Proc. Electr. Power, vol.151, no.1, pp.12-18, 2004.

[12] N. S. Bayindir, O. Kukrer, and M. Yakup, "DSP-based PLLcontrolled $50 \sim 100 \mathrm{kHz} 20 \mathrm{~kW}$ high frequency induction heating system for surface hardening and welding application”, Electric Power Appl., vol.150, no.3, pp.65-71, 2003.

[13] C.. P. Basso, "Switch-mode power supplies, SPICE simulations and practical designs", France: The McGraw Hill Companies, pp.189253, 2008.

[14] C. P. Basso, "Designing control loops for linear and switching power supplies", France: Artech House, pp.77-151, 2012.

Received: February 17, 2014

Revised: March 21, 2015

Accepted: June 9, 2015

(C) Haijun et al.; Licensee Bentham Open.

This is an open access article licensed under the terms of the Creative Commons Attribution Non-Commercial License (http://creativecommons.org/licenses/by$\mathrm{nc} / 3.0 /$ ) which permits unrestricted, non-commercial use, distribution and reproduction in any medium, provided the work is properly cited. 